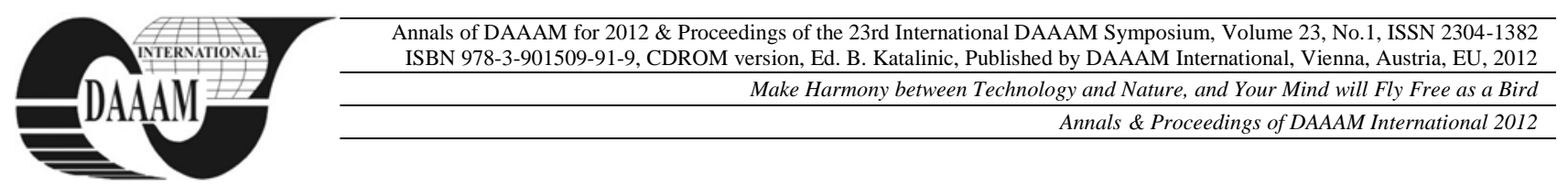

\title{
NEW METHOD OF CNC PROGRAMS CREATION BY GROUP TECHNOLOGY THEORY APPLICATION
}

\author{
NOVAK - MARCINCIN, J[ozef]; JANAK, M[iroslav]; NOVAKOVA - MARCINCINOVA, L[udmila] \& \\ TOROK, J[ozef]
}

\begin{abstract}
Creation of the control programs for controlling of the computer numerical controlled $(\mathrm{CNC})$ manufacturing machines is very important in manufacturing practice in this time. Manufacturing process of the parts with complex and free form figures are realized by NC manufacturing machines application. It is very difficult without application of personal computers with special software. Very often this software can be Computer Aided Manufacturing (CAM) systems. These programs for control of CNC manufacturing machines can be realised by other methods, too. In paper is presented new method of NC programs creation by Group Technology theory application.
\end{abstract}

Keywords: computer aided manufacturing, CNC programming, NC program creation, group technology, GroupNC program

\section{INTRODUCTION}

Numerical control (NC) refers to the automation of machine tools that are operated by abstractly programmed commands encoded on a storage medium, as opposed to controlled manually via handwheels or levers, or mechanically automated via cams alone. The first NC machines were built in the 1940s and 1950s, based on existing tools that were modified with motors that moved the controls to follow points fed into the system on punched tape. These early servomechanisms were rapidly augmented with analog and digital computers, creating the modern computer numerical control (CNC) machine tools that have revolutionized the machining processes. There exist two primary types of numerical control: CNC (Computer Numerical Control) where the control system of machine is directly connected to local computer and DNC (Distributed Numerical Control where is used flexible distributed controlling of several production machines from common centre. One from new method of CNC program realization is on the base of Group Technology theory application [1,2].

Group Technology (GT) is a manufacturing philosophy in which the parts having similarities (geometry, manufacturing process and/or function) are grouped together to achieve higher level of integration between the design and manufacturing functions of a firm. The aim is to reduce work-in-progress and improve delivery performance by reducing lead times. GT is based on a general principle that many problems are similar and by grouping similar problems, a single solution can be found to a set of problems, thus saving time and effort. The group of similar parts is known as part family and the group of machineries used to process an individual part family is known as machine cell. It is not necessary for each part of a part family to be processed by every machine of corresponding machine cell. This type of manufacturing in which a part family is produced by a machine cell is known as cellular manufacturing. The manufacturing efficiencies are generally increased by employing GT because the required operations may be confined to only a small cell and thus avoiding the need for transportation of inprocess parts [5].

\section{BASIC METHODS OF NC PROGRAM CREATION}

In manufacturing practice there are three main methods of NC programs creation: manual programming, conversational (shop-floor) programming and CAM system programming.

\subsection{Manual Programming}

For the some application, manual programming may be the best programming alternative. There are still a great number of companies who exclusively employ manual programming techniques. If, for example, only a few machine tools are used, and if the work performed by the company is relatively simple, a good manual programmer will probably be able to out-perform even a very good CAM system programmer. Or say a company dedicates the use of their $\mathrm{NC}$ equipment to a limited number of jobs. Once these jobs are programmed, there will never be a need to create more programs. This is another time when manual programming may make the best programming alternative. Even if a CAM system is used, there will be times when the NC program (at Gcode level) must be changed to correct mistakes during the verification of the program. Also, there will usually be an opportunity to optimize programs after running of the first few workpieces. If the programmer must use the CAM system to perform these very elementary changes to the NC program, a great deal of production time can be wasted [3].

\subsection{Conversational (Shop-floor) Programming}

This form of programming has become quite popular in recent years. With conversational programming, the program is created at the CNC machine. Generally speaking, the conversational program is created using graphic and menu-driven functions. The programmer will be able to visually check whether various inputs are correct as the program is created. When finished, most conversational controls will even show the programmer a tool path plot of what will happen during the machining cycle. Conversational controls vary substantially from one manufacturer to the next. In most cases, they can 
essentially be thought of as a single-purpose CAM system, and thus do provide a convenient means to generate part programs for a single machine. Be forewarned, though, that some of these controls, particularly older models, can only be programmed conversationally at the machine, which means you can't utilize other means such as off-line programming with a CAM system. However, most newer models can operate either in a conversational mode or accept externally generated G-code programs. There has been quite a controversy brewing over the wisdom of employing conversational controls. Some companies use them exclusively and swear by their use. Others consider them wasteful. Everyone involved with NC seems to have a very strong opinion (pro or con) about them. Generally speaking, companies who employ a limited number of people to utilize their NC equipment and run a wide variety of different workpieces tend to use and like conversational controls. In this kind of company, one person may be expected to perform many NC-related tasks. In many job shops, for example, the NC operator may be expected to set up tooling, make the workholding setup, prepare the program, verify and optimize the program, and actually run production. In this kind of company, anything that can be done to help the operator will streamline production. Conversational controls can dramatically reduce the time it takes the operator to prepare the program as compared to manual programming [6].

\subsection{Programming by CAM Systems}

CAM (Computer Aided Manufacturing) system is CA system, which is used for preparing of data and the programs for NC machines. This system is used in automated production of the mechanical parts, assemblies, etc. Particularly the geometrical and other data, which were obtained during the computer design of the part, are used in CAM system.

Postprocessor is tool, which transfers the geometrical data to code acceptable for control system, is part of $\mathrm{CAM}$ system. The CNC machines have different control systems and every systems need for transfer data different postprocessor. The libraries of these postprocessors and also modules for simulation and animation of production process are often integrated as a part of the CAM systems. User by these simulations can verify operations which are performed on the workpieces and so can prevent the collisions of the tool with fixtures or workpiece [2].

The one of properties, based on which is possible to class the CAM systems, is their completeness and compatibility with other CA systems, primarily with CAD systems. So, CAM systems are possible to class to two groups:

\section{CAM systems integrated in frame of the complex CAD/CAM/CAE systems.}

There are mainly products known as „big“ CAD/CAM/CAE systems, for example CATIA, NX former Unigraphics, Pro/Engineer and also „medium“ CAD/CAM systems, for example Cimatron or VisiCAM. The advantages of these systems are their completeness and integration of individual CAD, CAM and CAE modules. Therefore in these systems, the problems with transfer of geometrical data among individual parts and modules, are not existing.

\section{Specialized CAM, respectively CAD/CAM systems.}

This group is possible to divide into several groups: a)Complex CAM systems - for computer supporting of more technologies - for example SURFCAM, SmartCAM, Mastercam, AlphaCAM, etc.

b)Specialized CAM systems - for computer supporting of concrete technology - for example for milling PowerMILL and WorkNC, for production of the circuit boards ECAM 350, etc.

c)CAM superstructures of the specialized CAD systems. Most known is HyperMILL, which is superstructure of CAD systems AutoCAD and Mechanical Desktop.

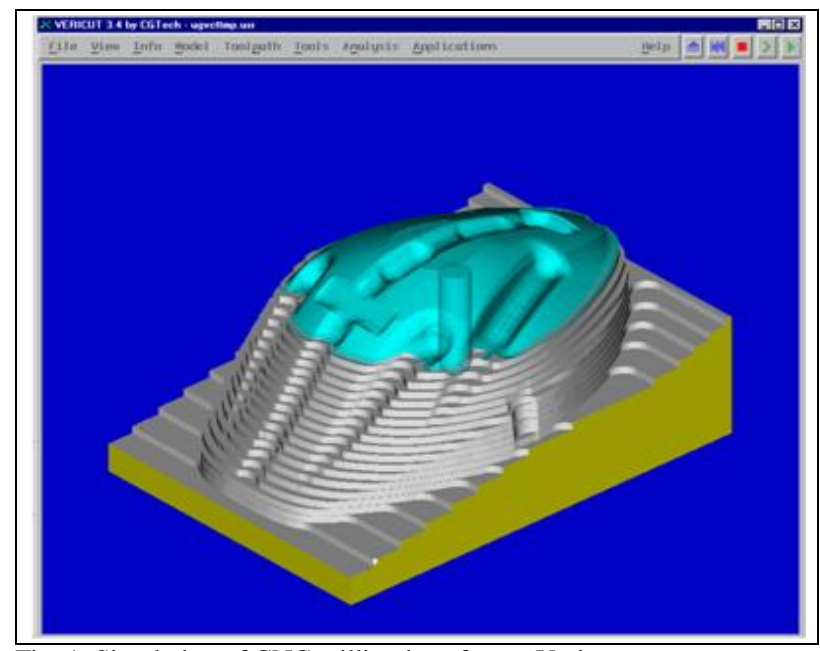

Fig. 1. Simulation of CNC milling in software Vericut

For the CAM systems is typically, that are focused on the computer aided manufacturing and their modules for creating the solid models are at low level (enable to create only wire-frame and 2D models, but not solid models). Solid models are needed to transfer from specialized CAD systems.

Some these CAM systems, which are very used and have the best quality, have modular structure. Therefore these CAM systems can create NC programs for lathes, milling, laser cutting, etc. They have the libraries of processors for transfer of data from CAM system to code for control system of machine. These systems can simulate the production process and so the some errors in $\mathrm{NC}$ program can be found, for example collision of the model and tool $[4,8]$.

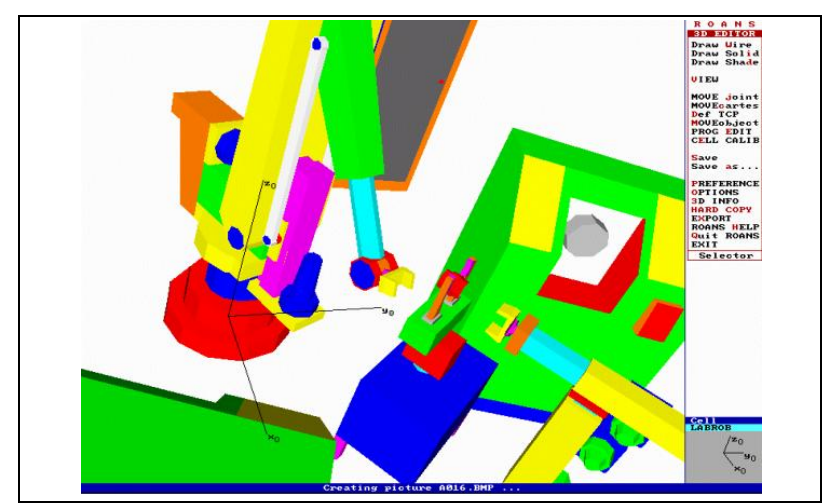

Fig. 2. NC Programming of robot workplace in system ROANS 
Mostly used and the best quality specialized CAM systems have modular structure enabling to create NC programs for 2-5 axis milling machines, lathes, wire cutters, water jet cutting equipment, laser cutting, plasma cutting, etc. They dispose by libraries of postprocessors serving for transfer of the generated tool paths to code which is suitable for control system of the production machine. Also, they dispose by modules for simulating the production process directly by computer, which allow to find incidental errors in NC program. For example collision of the model and tool, intersecting to material by fast feed speed when the work-piece is not suitable designed, option to see production process from various views, transparently, or in section [7, 9].

\section{CREATION OF NC PROGRAMS BY GROUP TECHNOLOGY THEORY APPLICATION}

A process plan is very important step in the product realization. This step takes a big effect for quality of product and for the cost of producing. Scheduling, production planning, part programming, etc., these inputs take a process plan. In the past the most of manufacturing systems were operated by humans. Therefore these systems were slowly for new information and inflexible. But today, the production method is gradually moving toward automation. Flexible automation has been especially stressed in recent years. Automated process planning or CAPP (Computer Aided Process Planning) is a way, how the computers can be used for generating a process plan. When this system is right set up can be a "reason" for dynamic response, fast plan generation and for example smooth interface between design and manufacturing functions. But the method for automating of process planning is not simply.

The development of CAPP started in the late sixties and in the early seventies the GT (Group Technology) was introduced. Standard process plan, part family, GT code and plan editing, they were terms, which were known for users, A few GT systems were developed, but these systems didn't generate a new process plan automatically.

NC program is similar as technological process plan, therefore, when GT can be used for automated creation of technological process plans, can be used for automated creation of NC programs, too.

Thousands of items are produced in manufacturing. Every part has a different size, function, shape etc. but when some people looks closely, some similarities among components can be found (Fig. 3). Parts classified and grouped into families produce a much more tractable database for management [5].

This simply concept has been in existence for a very long time, but not till 1958 Russian engineer S. P. Mitrofanov formalized this technology in his book "The Scientific Principles of Group Technology". Group technology (GT) has been defined as follows:

Group technology is the realization that many problems are similar, and that by grouping similar problems, a single solution can be found to a set of problems thus saving time and effort.
This definition is broad, but one usually relates this GT theory only to production applications. Group technology can be used in many different areas in production systems. In term of design components, a lot of components have a similar shape (Fig. 3). Therefore some these similar components can be grouped into the design families. Then the new design can be created by only the simply modifying of existing component design from the same family.

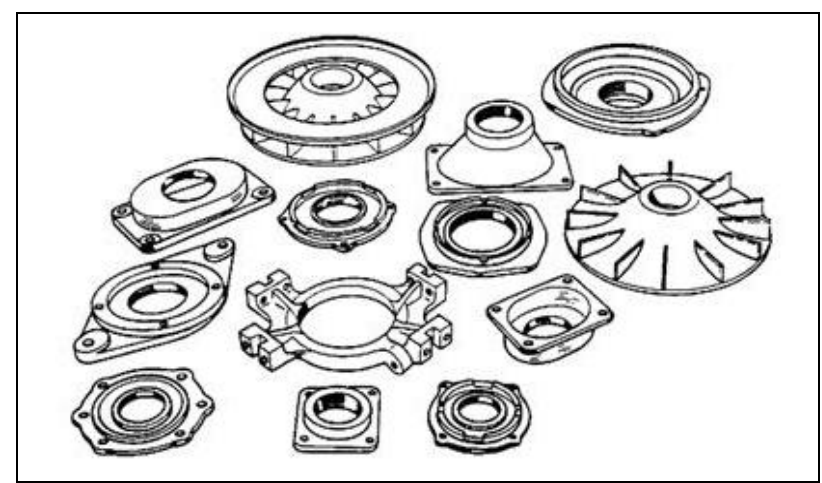

Fig. 3. Grouping parts according to their similarities

The familiar procedure of the generating of $\mathrm{NC}$ program using Group Technology contains of proposal of type representative of manufactured parts. Example of type representative for manufacturing of rotary parts is on Fig. 4.

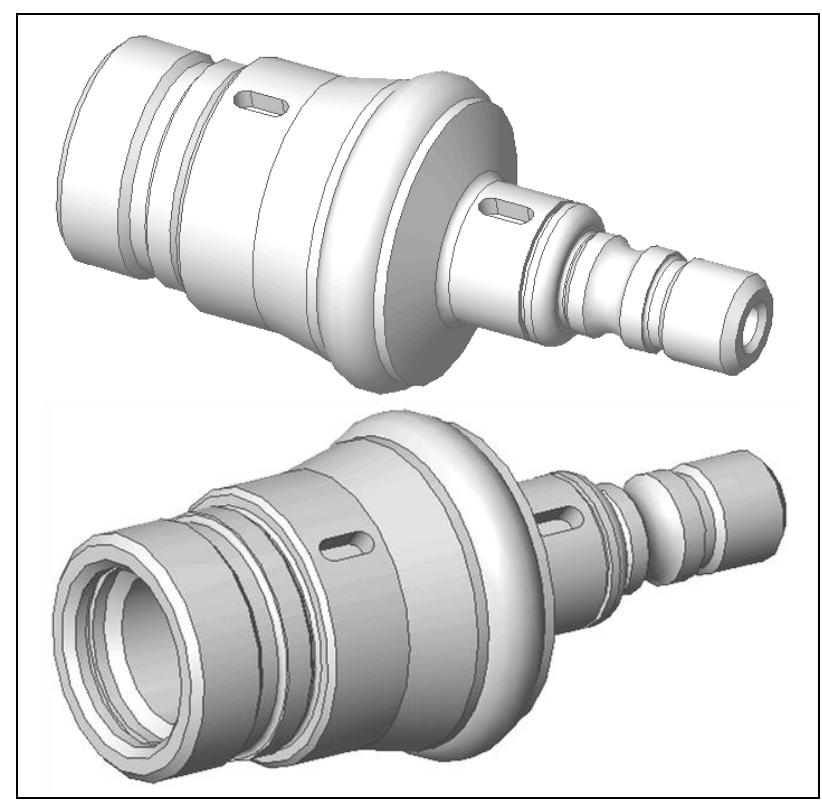

Fig. 4. Example of the complex part for NC cutting

The attitude based on principles of GT can be applied to the procedure of NC program creation. The algorithm must be followed for proper recognition of characteristic features and categorization of parts. The initial section of the algorithm includes the recognition and description of particular geometrical features, either they are of functional or only of geometrical nature. First, the basic geometrical shape of the part should be considered.

Then all the elements, like holes, slots, pockets and grooves should be taken into consideration and used for categorization to relevant group. 
This representative part has all types of shapes of surfaces, which are on components of production selection. Then for production of type representative, the creation of NC program is created by manual or using CAM system.

When the program is finished, subprograms are allocated to pertaining parts of the type representative. Thus, the special program can be created, or program environment for creation of new program based on the shape modification of produced components can be used with aid of combining each part of NC program. The part of algorithm of developing procedure for generation of NC programs using group technology is shown on Fig. 5 [2].

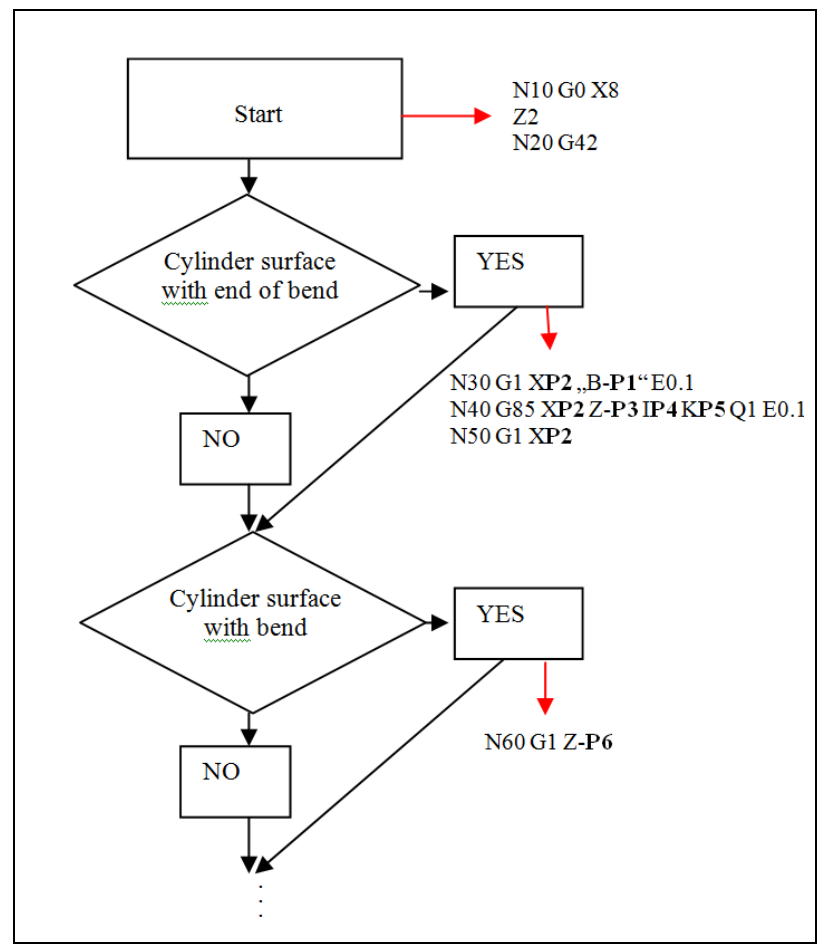

Fig. 5. Algorithm for NC program creation

On Faculty of Manufacturing Technologies of Technical University of Kosice with a seat in Presov, on Department of Production Technologies, the program for creation of NC programs with use of Group Technology is prepared. This program is named GroupNC and its first window is showed in Fig. 6.

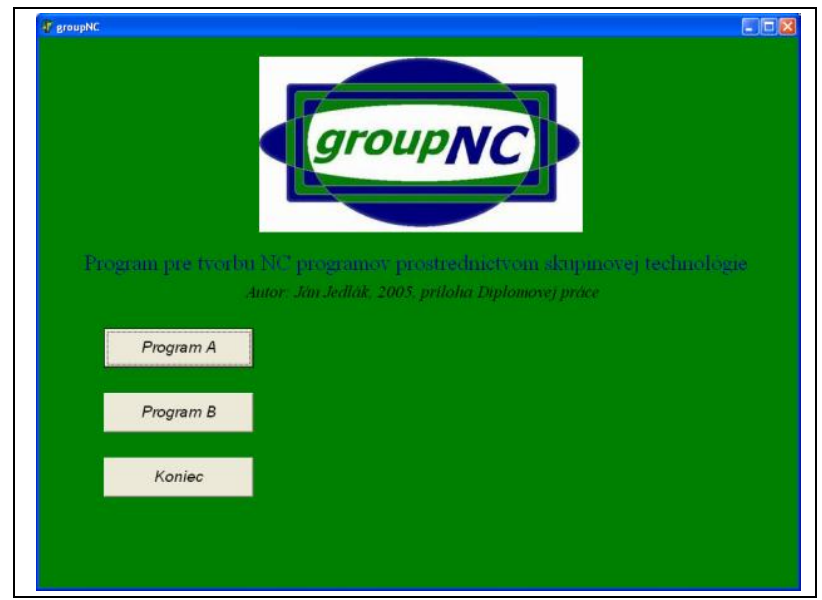

Fig. 6. Windows of GroupNC program

\section{CONCLUSION}

The aim of the paper is focused on the description of main methods of programs realization for the numerical controlled machines operation. After presentation of manual programming, conversational (Shop-floor) programming and realization of programs with use of CAM systems main part of the paper presents new original system of NC programming based on Group Technology theory application. After presentation of base principle of Group Technology theory in the paper is presented idea of its application in area of numerical control program realization. Next practical application of this method will present suitable way for applying process of technological standardization by using program applications of computer aided technical preparation of production, which is a part of whole managing and informative system of company in frame of computer integrated production.

\section{ACKNOWLEDGEMENTS}

Ministry of Education, Science, Research and Sport of SR supported this work, contract VEGA No. 1/0032/12, KEGA No. 002TUKE-4/2012 and ITMS project 26220220125.

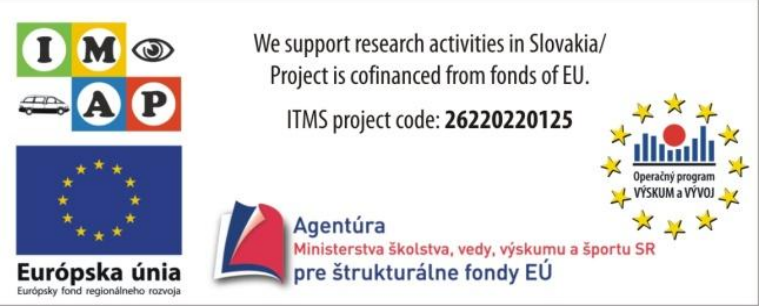

\section{REFERENCES}

[1] Antic, A.; Hodolic, J. \& Sokovic, M. (2006). Development of a Neural-Networks Tool-Wear Monitoring System for a Turning Process. Strojniški Vjesnik, Vol. 52, No. 11, pp. 763-776

[2] Fecova, V.; Marcincin, J. N.; Janak, M.; Barna, J. \& Marcincinova, L. N. (2011). Computer Aided Manufacturing Process Planning by Group Technology Application. In: Proceedings of 15th International Conference on Intelligent Engineering Systems INES 2011, Obuda University Budapest, Poprad, p. 81-84, ISBN 978-1-4244-8955-8

[3] Gots, I.; Zajac, J. \& Vojtko, I. (1995). Equipment for measuring the degree of wear to cutting tools. Technisches Messen, Vol. 62, No. 1, pp. 8-11

[4] Jurko, J.; Panda, A. \& Gajdos, M. (2009). Accompanying phenomena in the cutting zone machinability during turning of stainless steels. Int. Journal of Machining and Machinability of Materials, Vol. 5, No. 4, p. 383-400, ISSN 1748-5711

[5] Kuric, I. \& Kuba, J. (2006). Dynamic classification in CAPP. Annals of DAAAM for 2006 \& Proceedings of the 17th International DAAAM Symposium, Vienna, Katalinic, B. (Ed.), pp. 215-216, DAAAM, Vienna

[6] Lynch, M.: The Key Concepts of Computer Numerical Control. Web page: www.mmsonline.com/articles/cnc98intro.html

[7] Marcincin, J. N.; Brazda, P.; Janak, M. \& Kocisko, M. (2011) Application of virtual reality technology in simulation of automated workplaces. Technical Gazette, Vol. 18, No. 4, pp. 577-580, ISSN 1330-3651

[8] Matija, R.; Vojtko, I. \& Kocisko, M. (2011). Theoretical aspects of machining. In: Proceedings of the conference Transfer 2011, Casta Papiernicka. - Trencin, pp. 1-9, ISBN 978-80-8075-505-8

[9] Valicek J.; Hloch S. \& Kozak D. (2009). Surface geometric parameters proposal for the advanced control of abrasive waterjet technology. International Journal of Advanced Manufacturing Technology, Vol. 41. No. 3-4, pp. 323-328, ISSN 0268-3768 